\title{
Effectiveness of drought mitigation strategies in Bikita District, Zimbabwe
}

\author{
Terence Darlington Mushore, Chipo Muzenda/Mudavanhu, Theresa Makovere
}

Geography Department, Bindura University of Science Education, Bindura, Zimbabwe

\section{Email address:}

tdmushore@gmail.com (T. D. Mushore), chipomuzenda@gmail.com (C. Muzenda/Mudavanhu), tcmakovere@gmail.com (T. Makovere)

\section{To cite this article:}

Terence Darlington Mushore, Chipo Muzenda/Mudavanhu, Theresa Makovere. Effectiveness of Drought Mitigation Strategies in Bikita District, Zimbabwe. International Journal of Environmental Protection and Policy. Vol. 1, No. 4, 2013, pp. 101-107.

doi: 10.11648/j.ijepp.20130104.19

\begin{abstract}
Drought induced famine has been the worst disaster from which most rural people experience immense anguish. It still remains a National Policy agenda and a problem in most developing countries like Zimbabwe. Due to climate change, the impacts of droughts are expected to deepen where the capacity to adapt is low. Though it remains a challenge in communities, local people have devised different coping mechanisms based on the resources that are locally available but the effectiveness of these mechanisms are questionable. Therefore, using both qualitative and quantitative research methods this paper aims at identifying the drought mitigation strategies used in the Ward 2 of Bikita District, assess the impacts of these strategies and examine the challenges faced during attempts to implement them. Results indicated that in Ward 2 of Bikita District, people are using drought mitigation strategies which include food aid, food for work, and sale of livestock, remittances and irrigation scheme. It was also revealed that the most effective drought mitigation strategies were provision of food aid and food for work whereas the least effective were remittances and irrigation. The study also revealed that $72 \%$ of the community was not satisfied with the effectiveness of all the drought mitigation strategies being used. These strategies are held back by challenges in the Ward which include poor service delivery by NGOs and Government departments in mitigating droughts, poverty, corruption, lack of resources and unclear selection criterion of beneficiaries as well as lack of markets thereby leading to inefficiency of the drought mitigation strategies. The study recommended the construction of more dams and necessary infrastructure for irrigation, adoption of local knowledge into mitigation strategies, improving access to agricultural inputs and enhanced provision of technical assistance to farmers in the area.
\end{abstract}

Keywords: Drought, Mitigation, Strategies, Adaptation, Vulnerability, Bikita, Irrigation

\section{Introduction}

Drought is one of the most common disasters which can undermine livelihoods and well-being despite the use of various mitigation strategies (Mogotsi et al, (2012). It is a creeping phenomenon whose effects accumulate over time before they are felt and lingering on long after the actual event while problems associated with it can have economic, environmental and social impacts. They can cause decline in crop yields resulting in reduction in income for farmers which will cause increase in market prices of products (Dercon et al., 2005). Therefore, it is important to ensure that measures are in place to minimize impacts of drought on human beings and their livelihoods although the strategies also have limitations.

An effective drought mitigation and preparedness plan is based on established policies and institutional capacity.
Drought impacts and losses can be substantially reduced if authorities, individuals and communities are well prepared, ready to act and equipped with knowledge for effective drought management. Therefore, the goal of mitigation and preparedness is to reduce impacts of drought, reduce vulnerability and foster drought resilient societies (Ncube, 2010). According to Buckland et al., (2000), within the agricultural sector drought is arguably the most important climatic challenge and has major impacts on rural livelihoods. In most rural areas in Zimbabwe rain-fed agriculture is the basis of livelihoods such that fluctuations in annual rainfall cause corresponding variations in viability of agriculture. About $70 \%$ of the Zimbabwe`s population lives in rural areas and derive their livelihoods from subsistence agriculture and other rural activities (Buckland, et al., 2000).

In Zimbabwe food security was at a critical level, 
primarily due to the lack of food, as the country passed through the peak of the hunger season prior to the new harvest experienced in April 2008. However, the biggest challenge to farming and food security in Zimbabwe today is not funding, not skills shortage but climate change and global warming (FAO., 2008). In February, the rains tapered off causing extreme dry weather conditions in several provinces of the country (Ministry of Agriculture., 2008). There was a long dry spell which seriously damaged the crops and yields for the main season crops. The worst affected provinces included Masvingo, Manicaland, Mashonaland East and Matabeleland South (FAO., 2008). Changing climate and weather systems pose a serious threat to agriculture, as they have disrupted rains, caused droughts and resulted in higher average temperatures. Efforts should be made to effectively minimize the impacts droughts in view of climatic trends which point towards more frequent droughts in Southern Africa.

World Development Report (2010) revealed that the impacts of a changing climate are already being felt, with more droughts, floods, strong winds and heat waves and it will increasingly pose challenges to development. Agriculture is extremely vulnerable to climate change; higher temperatures eventually reduce yields of desirable crops while encouraging weed and pest proliferation. Although there will be gains in some crops in some other regions of the world, the overall impacts of climate change on agriculture are expected to be negative threatening global food security. In Bikita district, subsistence farmers are producing less on their fields as the years are progressing; as a result there is a food shortage and effects of drought are worsening with time. Rainfall is erratic, poorly distributed and falls predominantly for only a few months each year resulting in livelihood insecurity since water scarcity and food security are interrelated problems. The mitigation strategies are used by the households but the effects of drought are increasing demanding for continuous assessment and improvement of these coping mechanisms. There are also challenges associated with the implementation of the strategies and these should be identified and combated for to increase the effectiveness of the strategies. Therefore the study seeks to assess the mitigation strategies in order to reduce the impacts and challenges faced by households in mitigating droughts in Ward 2 of the Bikita District.

\section{The Bikita District}

The Bikita district is found in the Masvingo Province of Zimbabwe (Figure 1a) it is located about $80 \mathrm{~km}$ East of Masvingo town.

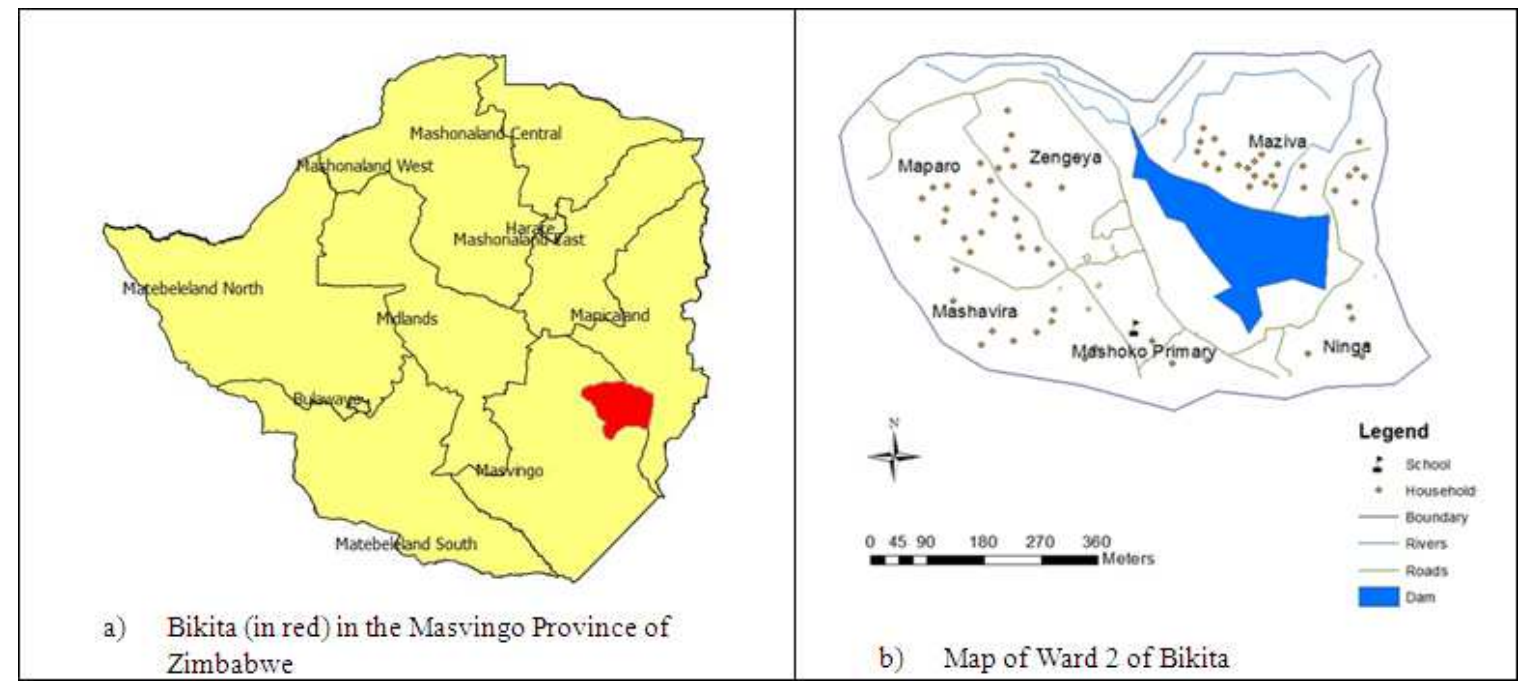

Figure 1. Map of Zimbabwe showing Bikita (a) and Map of Ward 2 of Bikita (b)

Table 1. The tools applied during the research

\begin{tabular}{lll}
\hline \multicolumn{1}{c}{ Method } & \multicolumn{1}{c}{ Description of use } & \multicolumn{1}{c}{ Stakeholders involved } \\
\hline Questionnaire & 29 members participated & Heads of households \\
Interview & 7 interviews were held & $\begin{array}{l}\text { Key informants: Ward Councillors, Headman and representatives of NGOs (CARE } \\
\text { International and Batanai HIV and AIDS Services Organization [BASO]). }\end{array}$ \\
Observation & $\begin{array}{l}\text { Guided visual observations done by } \\
\text { the researcher }\end{array}$ & Done as the researcher moved around and interacted with stakeholders. \\
Focus Group Discussions & 4 FDGs with 10 members per group. & Households heads \\
\hline
\end{tabular}


The area is mountainous characterized by steep slopes with sandy-loamy soils. It is subject to seasonal droughts (Unganai, 1996) and was particularly hard hit by 1992, 1994, 2002, 2004 and 2008 droughts. It covers an area of approximately $10,000 \mathrm{~km}^{2}$, and has a population of around 200,000 people. $81 \%$ of the district is classified as belonging to the natural regions (4 and 5) with mean annual rainfall ranging from $400 \mathrm{~mm}$ to $700 \mathrm{~mm}$. Agriculture is the major livelihood activity in the area with maize being the dominant crop grown (Matthew, 2003). The Figure 1b is showing study sites which include 5 villages namely Maziva, Ninga, Mashavira, Maparo and Zengeya in Ward 2 of Bikita District. The researchers used a sample size of 30 households which was selcted from 250 households at a represantative of $12 \%$ of the total population.

\section{Methodology}

A case study design was used because the research focused at a single entity or case which is the Ward 2 of Bikita District. The main tool used was the questionnaire although other tools were also employed which included the interviews, observational guides and focus group discussions. Major enquiries done were about

- $\quad$ Experiences of drought in the area

- Causes of vulnerability to drought

- The mitigation strategies used in the area

- The extent to which the communities are benefiting from the mitigation strategies

- $\quad$ The challenges encountered in mitigating droughts in the area and

- $\quad$ Possible solutions to the challenges.

\section{Results}

\subsection{Household Drought Mitigation Strategies}

The most common drought mitigation strategy was food aid which was acknowledged by all the 30 households sampled and the least common was irrigation acknowledged only by 4 of the 30 sampled households (Figure 2).

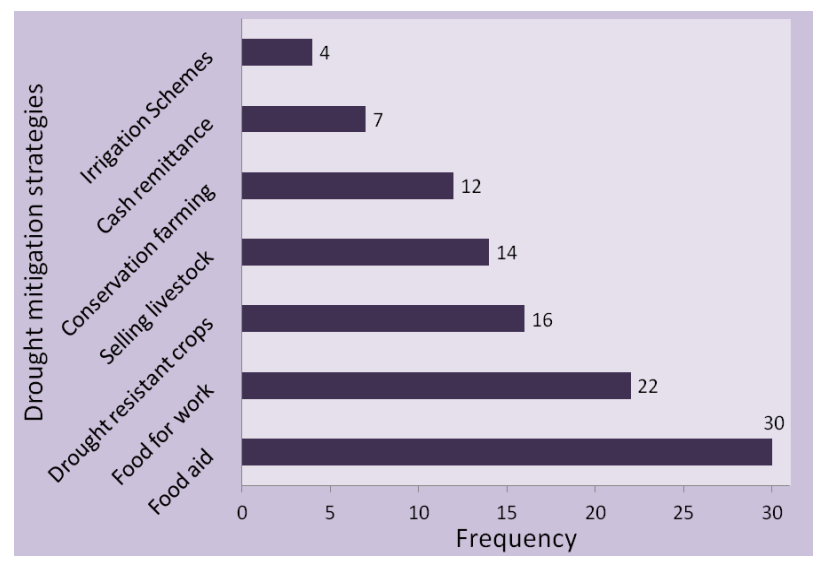

Figure 2. Household drought mitigation strategies
The other strategies included food for work, drought resistant crops, sale of livestock, conservation farming and remittances. The food aid is received from the Government and Care International only. Among drought mitigation strategies in Kenya food aid was also found to be the most common as indicated by Nyamangwe (1995). At an interview, organizations confirmed that they distribute food aid to ward 2 every year. An interviewee outlined that food aid given by organizations has been helping the households for a long time.

As illustrated in Figure 2 food for work was another strategy used by households with a frequency of 22, also the interviews revealed that food for work by NGOs is important since there is a gradual shift from free handouts to food for work. This was strongly backed by, Sweet (1998) whose research findings revealed that NGOs and the Government assisted in food for work projects in Namibia.

Some households responded that they employ drought resistant crops like sorghum, millet and rapoko. As also obtained by the research findings of Bhavnani et al (2008) the impacts of droughts were reduced by Ministry of Agriculture through introduction of drought resistant crops. Although access to the seeds is still very limited to the majority of the households and they rely heavily on maize production.

The responses from households as illustrated in Figure 2 showed that selling of livestock is one of the strategies employed by the communities. During droughts times the effects are seen through livestock death. Therefore the households are forced to sale their livestock at a lower price and barter trade one cattle with a bag of maize which is not profitable.

In Figure 2, about 7 households indicated reliance on remittances from relatives to keep food on the table and to meet their daily needs during droughts. The remittances are in the form of money, food and groceries. The remittances were sent by either relatives or family members who work in other areas in town or nearby growth points; Nyika and Jerera.

Irrigation schemes are not very common as few households benefited from (Figure 2). The locals generally do not directly benefit from the irrigation scheme that explains the least number of household using this strategy. There is need to consider that farmers benefit from irrigation.

\subsection{Food Crops}

Fifty four percent major of the respondents claimed the popularity of cultivation of maize above any other crops although drought resistant crops survive under harsh conditions more than maize (Figure 3). 


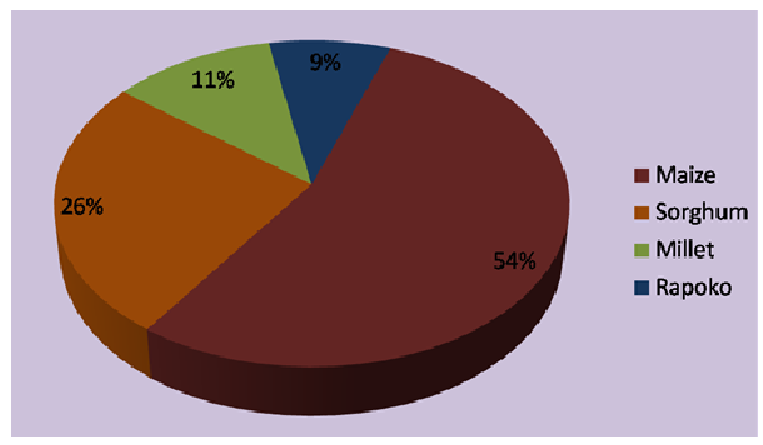

Figure 3. Food crops grown in Ward 2 of Bikita District

Sorghum is the most dominant drought resistant crop grown in the ward which was cited by $26 \%$. Sorghum is an important drought tolerant food grain in Zimbabwe and is mainly cultivated by Natural regions 4 and 5 which experienced harsh climatic conditions (Kaseke, 1996). According to Kaseke (1996), the majority of farmers were growing maize on large hectarage while small grains such as millet, rapoko and sorghum were given small hectarage. Millet and rapoko were not that common due to lack of access to seeds. This is true in Bikita District as most of the households still cultivate maize in marginal areas rather than drought resistant crops like sorghum, rapoko and millet.

\subsection{Sources of Food}

Own production is the most common source of food (Figure 4) because in rural areas majority of the households still depend on rain fed agriculture as their basis of livelihood although there are recurrent droughts. The households produce their own food through subsistence farming and maize being the dominant crop which is threatened by erratic rainfall in these southern parts of Zimbabwe resulting in low agricultural yields.

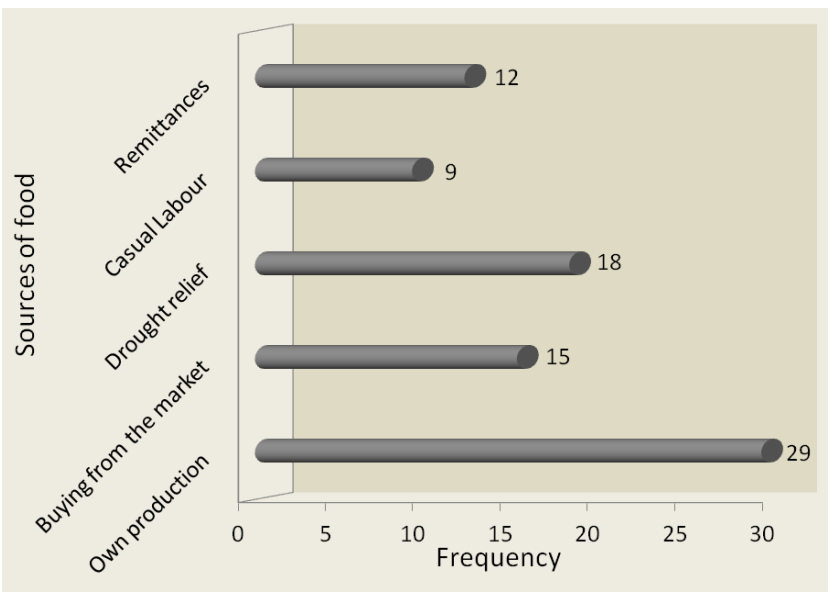

Figure 4. Sources of food in Ward 2 of Bikita District

Some farmers sell their produce and use the money to buy other food stuffs from the market as illustrated in Figure 4 that 15 households indicated that they acquire food from the market. As a drought strikes about 18 households acquire food from drought relief programs which include food aid and food for work programs. The households receive food aid and also benefit from food for work programs from the Government and NGOs such as SAT, BASO and Care. Casual labour is another strategy which helps people to have access to food through income generated from the labour. The households work in other people`s field and get food or money in return in what they called "Nhimbe"

\subsection{Impact of Drought Mitigation Strategies}

The impact of drought mitigation strategies was assessed basing on the availability of the food in different households. Figure 5 shows that food aid and food for work were cited as the most effective of the strategies in place.

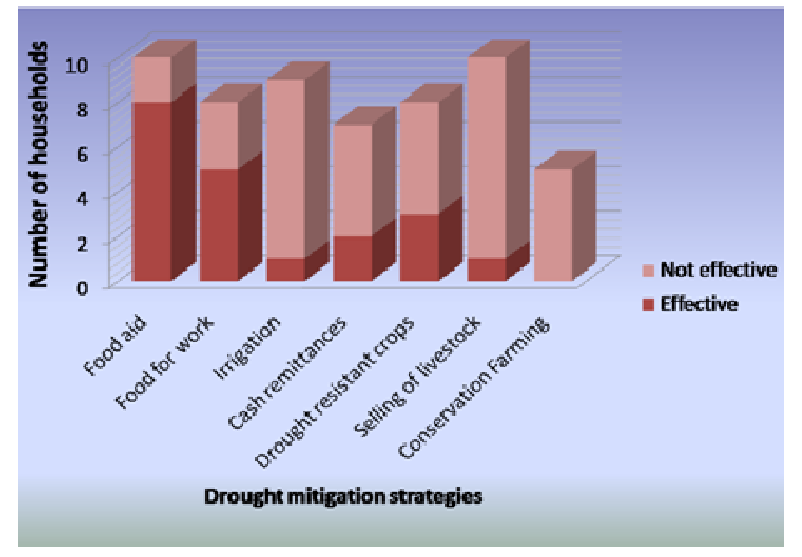

Figure 5. Perceived impacts of drought mitigation strategies in Ward 2

Food aid was very a popular drought mitigation strategy since the majority of the households receive food hand-outs during drought times when there are food shortages. Munro (2006) concurred that most vulnerable households have benefitted from food aid in Zimbabwe and this program has run for years since the 1991/92 drought. It reduces the extent of hunger and starvation although some of the households stated that they face challenges in accessing the aid.

Food for work was also labeled by participants as effective in the ward as people do gully reclamation and self-help projects to receive food from organizations in return. One of the organizations confirmed in an interview that households are working very well and the program is progressing. The households would work in projects while increasing food availability and reducing drought impacts. Some of the respondents argued that the program sometimes benefits the most vocal people in the ward leaving out the vulnerable groups.

Drought resistant crops are deemed less effective, since access to the crops is still very limited among households and the crops are mainly for beer brewing in the community. Therefore, drought resistant crops are popular for other uses than providing feed for the households. However, there are some households who are benefitting since the crops act as security during drought times (Figure 5). 
Selling of livestock is not an effective mitigation strategy in Ward 2 of Bikita District because it is not profitable during drought times. Drought affect farmers through livestock death since the distances to water sources increases for the animal and the animal feed (pastures) will be withered. The poor and most vulnerable do have no cattle or herds that are too small to allow them to destock.

Most of the households are not benefiting from irrigation because only a few have access to land or plots in the irrigation scheme. The scheme has managed to help only the Maziva village (Figure 1) where some are failing to fully utilize the plots due to lack of inputs and farming techniques.

Conservation farming was also viewed by the respondents as not effective in mitigating drought. In the ward there are organizations who participate actively in conservation farming of which the programs take a long period of time and require a lot of labour. A similar finding was obtained by Roncoli (2001), that labour constraints hindered soil and water conservation implementation by NGOs in Burkina Faso.

\subsection{Impact of Drought Mitigation Strategies on Households}

The households who were claimed that they were not benefiting from drought mitigation programs constituted $72 \%$ of the respondents. The majority of the households pointed out that the drought mitigation strategies were generally not effective in reducing food shortages and hunger. Recurrent droughts exacerbate the rural poverty since NGOs and the Government provides food handouts which are effective only during drought times while leading to dependency syndrome among households. Most of the food for work programs is not sustainable due to lack of integration and cooperation among stakeholders and the households. There is lack of creativity and willingness to work in projects so this will result in inefficiency of the programs.

The bulk of the households argued that the drought mitigation strategies especially coordinated by NGOs has created conflicts and hatred among the community especially on selection criterion. This has resulted in social exclusion especially of the poor of the poorest. Although, some households about $28 \%$ of the respondents argued during a FGD that the drought mitigation strategies were effective especially food aid because they receive free food handouts. Despite the fact that most of them create dependency syndrome and they are effective in the short run while in the long run hunger and starvation will persist.

\subsection{Challenges Faced in Drought Mitigation}

The households are facing quite a number of setbacks (Figure 6) in trying to reduce the impacts of drought and these have contributed to the ineffectiveness of drought mitigation strategies. Responses from questionnaires, interviews and focused group discussions pointed out that poverty, selection criterion, ineffective institutions, and increased frequency of droughts and remoteness of the area were the major challenges faced in trying to mitigate the impacts of droughts.

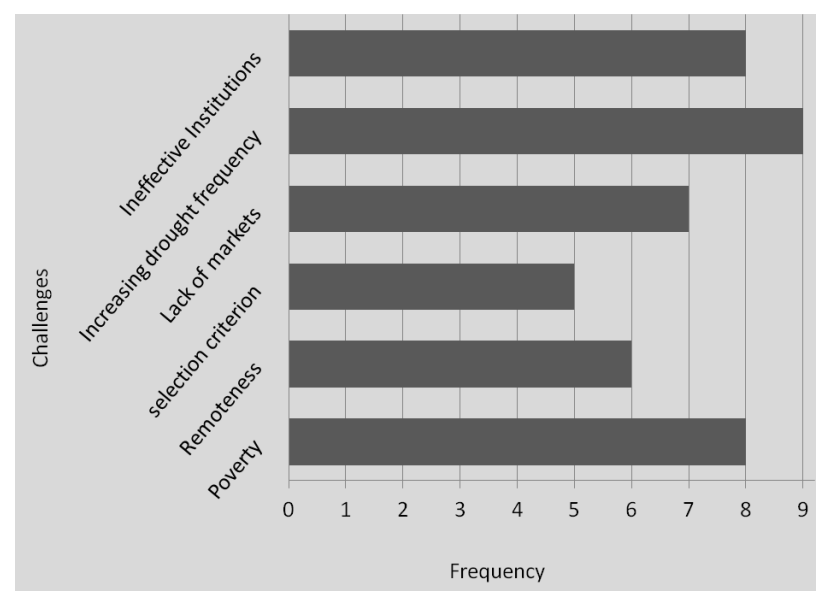

Figure 6. Challenges faced in mitigating drought in Ward 2

Households emphasized increasing frequency of drought as a clear and major challenge. The concern is growing that drought might become more frequent in the region as a result of global warming (UNFCC, 1998). Masvingo Province was affected by poor rainfall amounts as well as distribution especially in the most recent seasons (Ministry of Agriculture Zimbabwe, 2008, 2009, 2011, 2012; Mushore, 2013).

For the majority of the population, absolute lack of assets and means of livelihood and precarious economies with low coping or adaptive capacity present key factors that enhance vulnerability to impacts of drought. Poverty is the major problem which is exacerbated by drought effects as indicated by Maphosa (1994). The respondents mentioned that due to lack of capital they do not have access to inputs such as fertilizer, seeds and farming equipments.

During a FDG the households revealed that there are no markets for their produce especially vegetables and drought resistant crops such as millet and rapoko so the majority cultivated maize for food production. A similar finding was found by Chazovachii et al., (2010), there is no market for drought resistant crops and people are only relying on the local market. They said the ears of millet, rapoko and sorghum plants might not ripen at the same time thus they may have to be more than one harvest; hence, the majority of villagers opted for maize.

The geographic location and remoteness of the ward makes it more vulnerable to droughts since the area is in Region 4 and 5 and is isolated from market centers as Growth Points. The poor road networks and communication networks makes the area inaccessible as the roads are very poor such that the donors and investors shun away this ward. This isolation due to a lack of infrastructure may limit choices and coping strategies during times of stress and drought.

There is lack of integration and coordination among Government departments, NGOs and other institutions in disaster management. Institutions face a number of 
challenges which include political interferences, lack of resources and lack of coordination in drought management. At a FGD the respondents stated that only a few benefit from programs since there is political interference thus the most vocal benefit more than the poor of the poorest.

The households were benefitting from institutions to a lesser extent since most of the assistance is helpful in the short run just after drought but in the long run there are persistent food shortages. Respondents also cited that selection of beneficial to be incorporated in drought mitigation strategies is usually done by the most vocal persons and political elites. Consequently, corruption and favoritism make only a few to benefit from the programs done by agencies. The vulnerable households usually suffer the most if they are not included in the program.

\section{Recommendations}

It is recommended that more dams and reservoirs should be constructed in Ward 2 for irrigation purposes and the community should fully utilize the existing irrigation infrastructure. Civil Society should involve the local traditional drought mitigation knowledge and practices as this could provide the basis for development of more effective strategies. Farmers should be provided with technical assistance and other farming technologies to improve agricultural yields by such organizations as AGRITEX amongst others. The farmers should have access to drought resistant crops since they sustain in drought prone areas than maize. They should be encouraged to cultivate small grains such as rapoko and millet and market for these should be established as a trigger for production. Off-farm income or income diversification should be promoted by the organizations to avoid the risk associated with relying on farming alone.

\section{Conclusions}

In the study households employed a number of drought mitigation strategies and they heavily rely on drought relief from NGOs and Government. Such drought response measures often result in immediate effects on people's lives and livelihoods in the short term especially drought relief. However, these efforts are also creating dependencies and other new vulnerabilities and may not reduce the underlying vulnerabilities. Although it is an important safety net (drought relief) as shown in the study, and often politically appealing it should not be the primary focus on drought risk reduction.

The drought mitigation strategies have not been fully effective in Ward 2 of Bikita. The majority of the households argued that they are not benefitting from the strategies and there are persistent food shortages. The study revealed that food availability most of the strategies are not sustainable as they are short term and vulnerability remains high after them.

A number of challenges which include poverty, increased drought frequency and selection criterion for beneficiary of relief programs have contributed greatly to the perceived ineffectiveness of drought mitigation strategies in Ward 2 of Bikita District. The challenges have reduced the capacity of the households to reduce the drought impacts and acquire food surplus. The study recommended strategies which capacitate the community and are sustainable.

\section{References}

[1] Bhavnani, R., Vordzoghe, S., Owur, M., \& Bousquet, F. (2008). Report on the status of disasters and Risk reduction in the Sub Saharan African Region.

[2] Buckland, R., Eele, G., \& Mugwara, R. (2000). Humanitarian Crisis and natural disasters, A SADC perspective, Food and Humanitarian security. Frank Cass Production. London.

[3] Chazovachii, B., Chigwenyu, A., \& Mushuku, A. (2010). Adaptation of Climate Resilient Rural Livelihoods Through Growing of Small Grains in Munyardzi Communal Area. Gutu District. African Journal of Agricultural Research, 8, 1335-1345.

[4] Dercon, S., Haddinolt, J., \& Woldehanna, T. (2005). Shocks and Consumption in Ethopia. Journal of African Economies, 14(4), 559-585.

[5] FAO. (2008). Zimbabwe 2008/07 Agricultural Season Update.

[6] Kaseke, E. (1996). Social Security Systems in Rural Zimbabwe. Weaver press, Harare.

[7] Maphosa, B., (1994). . (1994). Lessons From the 1992. Drought in Zimbabwe: The Quest for Alternative Food Policies Nodic Journal of Africa Studies, 3(1), 53-58.

[8] Matthew, B. (2003). The Ownership and Management of Production. Water point Gardens in a time of Drought, Zimbabwe. International Symposium on Water, Poverty and Productive uses of Water at the Household Level, 140-154.

[9] Ministry of Agriculture Zimbabwe. (2008). Second Round Crop and Livestock Assement Report.

[10] Ministry of Agriculture Zimbabwe. (2009). First Round Crop and Livestock Assessment Report.

[11] Ministry of Agriculture Zimbabwe. (2011). Second Round Crop and Livestock Assessment Report.

[12] Ministry of Agriculture Zimbabwe. (2012). Second Round Crop and Livestock Assessment Report.

[13] Ministry of Agriculture. (2008). Second Round Crop and Livestock Assessment Report. Harare.

[14] Mogotsi, K., Nyangito, M. M., \& Nyariki, D. M. (2012). The Role of Drought among Agro-Pastoral Communities in Semi-Arid Environment. The Case of Botswana. Journal of Arid Environments, 91, 38-44.

[15] Munro, L. T., (2006). . (2006). Zimbabwe's Drought Relief Program in the 1990s. A re-Assessment using the National Household Survey Data. Journal of Contingencies and Crisis Management, 14(3), 125-141. 
[16] Mushore, T. D. (2013). Climatic Changes, Erratic Rains and the Necessity of Constructing Water Infrastructure: Post 2000 Land Reform in Zimbabwe. International Journal Of Scientific \& Technology Research 2(8).

[17] Ncube, S. P. (2010). Reservoir Operation under Different Climate Scenarios: Case of Roswa Dam, Bikita District University of Zimbabwe, Faculty of Engineering, Harare.

[18] Nyamangwe, N. (1995). Famine Mitigation in Kenya: Same practices, impact lessons. Journal of The Middle State Geographer, 28, 37-44.

[19] Roncoli, C., Ingram, K., \& Kirshen, P. (2001). The Costs and Risks of Coping with Drought Livelihood Impacts and
Farmers Responses in Burkina Faso. Climate Research, Volume, 19(119-132).

[20] Sweet, J. (1998). Livestock coping with drought: Namibia a case study. Nerma Livestock Development Project, Tsuneb.

[21] UNFCC. (1998). Expected Impacts of Climate Change Vulnerability and Adaptation Assessments in Zimbabwe.

[22] Unganai, L. S. (1996). Historic and future climatic change in Zimbabwe. Climate Research, 6, 37-145.

[23] World Development Report. (2010). Vulnerability Preparedness and Mitigation. Natural and Anthropogenic Disasters. Springer, New Delhi. 